\title{
Identifying socio-demographic risk factors for suicide using data on an individual level
}

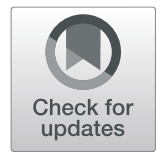

Guus Berkelmans ${ }^{1 *}$, Rob van der Mei ${ }^{1,2}$, Sandjai Bhulai ${ }^{2}$ and Renske Gilissen ${ }^{3}$

\begin{abstract}
Background: Suicide is a complex issue. Due to the relative rarity of the event, studies into risk factors are regularly limited by sample size or biased samples. The aims of the study were to find risk factors for suicide that are robust to intercorrelation, and which were based on a large and unbiased sample.

Methods: Using a training set of 5854 suicides and 596,416 control cases, we fit a logistic regression model and then evaluate the performance on a test set of 1425 suicides and 594,893 control cases. The data used was microdata of Statistics Netherlands (CBS) with data on each inhabitant of the Netherlands.

Results: Taking the effect of possible correlating risk factors into account, those with a higher risk for suicide are men, middle-aged people, people with low income, those living alone, the unemployed, and those with mental or physical health problems. People with a lower risk are the highly educated, those with a non-western immigration background, and those living with a partner.

Conclusion: We confirmed previously known risk factors such as male gender, middle-age, and low income and found that they are risk factors that are robust to intercorrelation. We found that debt and urbanicity were mostly insignificant and found that the regional differences found in raw frequencies are mostly explained away after correction of correlating risk factors, indicating that these differences were primarily caused due to the differences in the demographic makeup of the regions. We found an AUC of 0.77 , which is high for a model predicting suicide death and comparable to the performance of deep learning models but with the benefit of remaining explainable.
\end{abstract}

Keywords: Suicide, Machine learning, Big data, Risk factors

\section{Introduction}

Suicide is a complex issue that involves multiple factors. Many researchers have looked into risk factors for suicide. However, much of this research looks at risk factors in isolation, or corrected only for age or gender [1-5]. As a consequence, risk factors found in these studies could simply be a proxy for other risk factors due to the fact that they are correlated (for example, education level and income). Additionally, many studies are of limited size, and are usually non-representative of

\footnotetext{
*Correspondence: g.a.berkelmans@cwi.nl

${ }^{1}$ Centrum Wiskunde \& Informatica, Science Park 123, 1098 XG Amsterdam, Netherlands

Full list of author information is available at the end of the article
}

the population as a whole due to the way the selection procedure was set up, for example, a clinical setting [1].

Knowing that suicide is rarely related to just one risk factor, this study quantifies the effect of individual characteristics as accurately as possible by correcting for correlation of characteristics. Furthermore, this study uses all suicide cases in the Netherlands (around 1900 suicides are reported every year) and a large randomly selected sample of control cases drawn from the full population. This avoids issues of small sample size and selection bias.

To our knowledge, only Gradus et al. [6] used such an approach before in Denmark. They found sex-specific risk profiles for suicide, focusing their risk profiles 
mainly on medical data. However, in this paper, we focus on socio-demographic risk factors.

This study decorrelates the effects of the risk factors to obtain odds ratios which take into account the proxy effects to the other risk factors. Moreover, we look across multiple years (2014-2017) and at a large number of socio-demographic factors. In this way, we obtain risk factors that are both robust to intercorrelation as well as to events that raise the risk among a certain subpopulation.

\section{Methods}

The primary aim of the study is to find risk factors for suicide that are robust to intercorrelation. In this way we can be sure that the risk factors are not proxies for the numerous other risk factors that are included in the study. Additionally, a secondary aim is to make sure that we can be sure that the risk factors found are based on a large unbiased sample.

The data used was the micro-data of Statistics Netherlands [7]. Statistics Netherlands collects data on each inhabitant of the Netherlands (approximately $17,000,000$ inhabitants) from various sources, which are required to provide this information by law. This data includes socio-demographic characteristics like birth date, gender, marital status, type of household, role in household, ethnicity, income, social benefits and in case of death it includes cause and date of death.

Due to the privacy-sensitive nature of the data, it is not freely accessible, nor is the data itself allowed to be published. Access has to be granted by Statistics Netherlands on a project-to-project basis, which was granted for this project. It is only possible to work with the data via remote connection to their secure servers, and any output is checked on whether it satisfies the privacy regulations before it is released for publication.

We limited ourselves to the period of 2014-2017 since some of the databases for 2018 and later were still undergoing data quality checks. Additionally, some databases had a different format prior to 2014 so did not include all of the characteristics of interest prior to 2014. Therefore, we could not analyze data from before 2014 alongside data from the period 2014-2017 while retaining all characteristics of interest. From the dataset of the years 2014-2017, those individuals who died by suicide were identified based on their cause of death, as established by coroners (ICD-10 codes for external causes: intentional selfharm (X60-X84)). The coroner is contacted when there is doubt as to whether a person died of natural causes. The coroner is always contacted when the deceased is underage (in the Netherlands, this means younger than 18 years old).

\section{Statistical analysis}

The binomial logit model was used (commonly referred to as logistic regression) to decorrelate effects. Sociodemographic characteristics of each inhabitant aged 10 and up on the 31st of December (of 2013, 2014, 2015, or 2016) were categorised. We limited ourselves to ages 10 and up since Statistics Netherlands doesn't report on suicides among youths under 10 years old, due to it being an extremely rare event. We then modelled the probability of suicide according to a binomial logit model such that

$$
P\left(S_{n} \mid \overrightarrow{x_{n}}\right)=\frac{e^{V\left(\overrightarrow{x_{n}}\right)}}{1+e^{V\left(\overrightarrow{x_{n}}\right)}},
$$

where $S_{n}$ is the event that individual $n$ dies due to suicide in the following year, and

$$
V\left(\overrightarrow{x_{n}}\right)=\beta_{0}+\sum_{j=1}^{k} \beta_{j}\left(\overrightarrow{x_{n}}\right)_{j}
$$

where $\left(\overrightarrow{x_{n}}\right)_{j}$ is 1 if individual $n$ has characteristic $j$ and 0 otherwise, and $k$ is the total number of possible characteristics. This results in characteristics $j$ having an odds ratio (OR) of $e^{\beta_{j}}$.

Since suicide is a quite rare event (roughly 1 per 10,000 people per year), the odds which are defined as $\mathrm{O}=\frac{p}{1-p}$ are extremely close to the actual probability.

The main advantage of such a model is that proxy effects are corrected for as long as the proxy is also included in the model. Therefore, risk groups that are heavily correlated with, e.g., age, gender, income are corrected for. Though there is still an underlying assumption that risk factors increase risk independently to a certain degree, this assumption is significantly weaker than if one considered the risk factors in isolation or if corrected for a small number of risk factors.

Estimation was done using the Python package biogeme [8]. This package estimates the model parameters using maximum likelihood estimation by gradient descent. It has been proven [9] that in the case of the binomial logit model, this always converges to the optimal model with regards to the training error. This means we do not have to worry about local optima. Additionally, the package provides us with standard errors on the parameter estimation, allowing us to form confidence intervals and do tests of significance. The tests of significance done are t-tests (which show how many standard deviations of the estimator it is distanced from 0 ).

First, estimation was done on a training set. This training set consisted of both people who died by suicide as well as a group of people who did not die by suicide. 
The people who died by suicide were included with independent probability 0.8 (ended up being 5854 cases). The people who did not die due to suicide were included with independent probability 0.01 (ended up being 596,416 cases). Due to the way the sampling was done, all bias introduced is introduced into the $\beta_{0}$ parameter. We, therefore, do not report this parameter. The selection procedure of the training set does not introduce any bias into the other parameters.

Secondly, we generated a test set. This test set contained the remaining suicide cases (1425 cases). Additionally, it contained cases of people who did not die by suicide. These cases were again included with probability 0.01 , in such a way that it contains no cases included in the training set.

We then estimated the predicted risk of suicide for this test set. From these predictions, we calculated the sensitivity (the proportion of correctly classified cases among suicide victims) and specificity (the proportion of correctly classified cases among those who did not die due to suicide) for various risk thresholds. We then plotted the sensitivity and specificity against each other. In this way, we obtained the receiver operating characteristics curve (ROC curve). We then calculated the area under the ROC curve (AUC) to estimate model performance. The AUC is also the probability that a random case of death by suicide gets a higher predicted risk than a random case of someone who does not die due to suicide.

\section{Results}

The parameters we estimated (i.e., the $\beta_{j}$ parameters and associated standard errors, t-tests, and odds-ratios) for the binomial logit model are shown in Table 1. When we talk about increased risk we are talking about increases to the odds of suicide.

Taking the effect of possible correlating risk factors into account, significant increases in risk in all age groups were observed compared to those aged 10 to 19 . We see large increases in particular among people aged between 40 and 49 (OR 5.70, 95\% CI [4.57,7.24]), between 50 and 59 (OR 6.69, 95\% CI [5.37,8.33]), and between 60 and 69 (OR 4.76, 95\% CI [3.82,5.93]).

The fact that males die more often due to suicide than females (OR 2.60, 95\% CI [2.46,2.77]) still holds when corrected for other characteristics. Furthermore, having mental health problems (OR 7.69, 95\% CI [7.24,8.17]) as well as physical health problems as measured through healthcare costs (up to OR 2.23, 95\% CI $[2.01,2.46]$ ) are major risk factors. Additionally, living alone (OR 1.75, 95\% CI $[1.49,2.05])$, and all forms of unemployment, especially those that have been found unfit for work (UFW; having an OR of 1.89, 95\% CI [1.75,2.05]), increase the risk of suicide.
Looking at protective factors, the analyses show that people with a high level of education have a low risk (OR 0.82, 95\% CI $[0.74,0.90])$. Low-risk people are also those with a non-western immigration background (OR $0.63,95 \% \mathrm{CI}[0.57,0.69])$ and 1st generation immigrants (OR 0.72, 95\% CI $[0.66,0.78]$ ). Also being married or having children is a protective factor for a couple living together (OR 0.64, CI 95\% [0.54.0.75] for a married couple without kids, OR $0.63,95 \%$ CI $[0.52,0.77]$ for a non-married couple with kids). These effects are weaker when the other effect is already present (OR 0.58, 95\% CI $[0.48,0.69])$.

Having a higher income is also a protective factor. This holds for both personal income (up to OR 0.64, $95 \%$ CI $[0.41,1]$ ) as well as household income (up to OR $0.63,95 \% \mathrm{CI}[0.50,0.80])$. Interestingly, household wealth does not appear to be a protective factor. It even increases risk in the wealthiest category (Table 1). We observe urbanicity and regional differences being mostly non-significant.

Figure 1 shows the approximate ROC (based on percentiles to preserve privacy). Each point on the curve corresponds to a threshold and shows the proportion of people who died by suicide that are above the threshold (the sensitivity) on the y-axis. On the $x$-axis, it shows the proportion of people in the control group who are above the threshold. The curve shows a trade-off between true and false positives and allows for an informed choice of thresholds for risk groups. The AUC, which is based on the full plot, is 0.77 . This means that the probability that an individual in the sample of those dying by suicide will get a higher predicted risk than an individual in the control set is $77 \%$. A fully random model would have an AUC of 0.50, while a perfect model would have an AUC of 1.

\section{Discussion}

To our knowledge, this is the first study done into suicide on socio-demographic factors with such a large and unbiased sample, where, due to the level of detail of the data, analyses could be done to control for many characteristics, giving us very robust risk factors. We found that previously discovered risk factors for suicide (middle-age, male gender, and unemployment (as measured through benefits)) remain elevated even when corrected for a wide array of socio-demographic characteristics. The same holds for commonly found protective factors for suicide, like having a higher income or immigration background.

Most increased risk came from being a recipient of mental health care (which includes being an inpatient as well as being an outpatient), which can be expected knowing that approximately $87 \%$ of people 
Table 1 Socio-demographic risk and protective factors for suicide in the Netherlands

\begin{tabular}{|c|c|c|c|c|c|c|c|}
\hline Categories & Characteristics & $\begin{array}{l}\text { Beta } \\
\text { Parameters }\end{array}$ & Std. errors & t-tests & Odds-ratio & $\begin{array}{l}\mathrm{N}(\%) \text { training } \\
\text { set }\end{array}$ & $\begin{array}{l}\mathrm{N}(\%) \text { suicides } \\
\text { training set }\end{array}$ \\
\hline \multirow[t]{8}{*}{ Age } & 10 to 19 & 0 & Fixed & Fixed & 1 & $79,525(13 \%)$ & 195(3\%) \\
\hline & 20 to 29 & 0.95 & 0.10 & $9.40^{* * *}$ & 2.58 & $80,131(13 \%)$ & $541(9 \%)$ \\
\hline & 30 to 39 & 1.39 & 0.11 & $12.52^{* * *}$ & 4.01 & $79,243(13 \%)$ & $677(12 \%)$ \\
\hline & 40 to 49 & 1.74 & 0.11 & $15.82^{* * *}$ & 5.70 & $97,348(16 \%)$ & $1159(20 \%)$ \\
\hline & 50 to 59 & 1.9 & 0.11 & $17.27^{* * *}$ & 6.69 & $97,423(16 \%)$ & $1487(25 \%)$ \\
\hline & 60 to 69 & 1.56 & 0.11 & $13.68^{* * *}$ & 4.76 & $82,917(14 \%)$ & $945(16 \%)$ \\
\hline & 70 to 79 & 1.40 & 0.12 & $11.57^{* * *}$ & 4.06 & $53,098(9 \%)$ & 533(9\%) \\
\hline & 80 or older & 1.13 & 0.13 & $8.83^{* * *}$ & 3.10 & $32,585(5 \%)$ & $317(5 \%)$ \\
\hline \multirow[t]{2}{*}{ Gender } & Female & 0 & Fixed & Fixed & 1 & $305,867(51 \%)$ & 1887(32\%) \\
\hline & Male & 0.96 & 0.03 & $30.00^{* * *}$ & 2.60 & $296,403(49 \%)$ & $3967(68 \%)$ \\
\hline \multirow{9}{*}{$\begin{array}{l}\text { Personal } \\
\text { income/year }\end{array}$} & Less than 10,000 & 0 & Fixed & Fixed & 1 & $170,265(28 \%)$ & $963(16 \%)$ \\
\hline & 10,000 to 20,000 & -0.12 & 0.05 & $-2.42^{*}$ & 0.89 & $133,646(22 \%)$ & 1878(32\%) \\
\hline & 20,000 to 30,000 & -0.21 & 0.06 & $-3.63^{* * *}$ & 0.81 & $96,273(16 \%)$ & $1120(19 \%)$ \\
\hline & 30,000 to 40,000 & -0.17 & 0.07 & $-2.49^{*}$ & 0.85 & $75,794(13 \%)$ & $816(14 \%)$ \\
\hline & 40,000 to 50,000 & -0.31 & 0.08 & $-3.89^{* * *}$ & 0.73 & $48,697(8 \%)$ & $426(7 \%)$ \\
\hline & 50,000 to 75,000 & -0.31 & 0.09 & $-3.52^{* * *}$ & 0.74 & $51,114(8 \%)$ & $431(7 \%)$ \\
\hline & 75,000 to 100,000 & -0.27 & 0.12 & $-2.23^{*}$ & 0.76 & $14,750(2 \%)$ & $124(2 \%)$ \\
\hline & 100,000 to 150,000 & -0.27 & 0.15 & -1.72 & 0.77 & $8003(1 \%)$ & $66(1 \%)$ \\
\hline & More than 150,000 & -0.44 & 0.22 & $-1.97^{*}$ & 0.64 & $3728(1 \%)$ & $30(1 \%)$ \\
\hline \multirow{8}{*}{$\begin{array}{l}\text { Household } \\
\text { income/year }\end{array}$} & Less than 20,000 & 0 & Fixed & Fixed & 1 & $52,404(9 \%)$ & $1147(20 \%)$ \\
\hline & 20,000 to 40,000 & -0.18 & 0.05 & $-3.49 * * *$ & 0.84 & $129,459(21 \%)$ & 1712(29\%) \\
\hline & 40,000 to 60,000 & -0.31 & 0.07 & $-4.65^{* * *}$ & 0.74 & 105,090(17\%) & $958(16 \%)$ \\
\hline & 60,000 to 80,000 & -0.31 & 0.08 & $-4.11^{* * *}$ & 0.73 & $95,590(16 \%)$ & $711(12 \%)$ \\
\hline & 80,000 to 100,000 & -0.32 & 0.08 & $-3.77^{* * *}$ & 0.73 & $75,645(13 \%)$ & $508(9 \%)$ \\
\hline & 100,000 to 150,000 & -0.43 & 0.09 & $-4.85^{* * *}$ & 0.65 & $98,135(16 \%)$ & $557(10 \%)$ \\
\hline & 150,000 to 200,000 & -0.46 & 0.12 & $-3.86^{* * *}$ & 0.63 & $28,459(5 \%)$ & $151(3 \%)$ \\
\hline & More than 200,000 & -0.26 & 0.14 & -1.88 & 0.77 & $17,488(3 \%)$ & $110(2 \%)$ \\
\hline \multirow[t]{14}{*}{ Household wealth } & Less than $-100,000$ & 0.09 & 0.11 & 0.84 & 1.10 & $13,279(2 \%)$ & $98(2 \%)$ \\
\hline & $-100,000$ to $-80,000$ & 0.45 & 0.13 & $3.38^{* * *}$ & 1.57 & $6008(1 \%)$ & $63(1 \%)$ \\
\hline & $-80,000$ to $-60,000$ & 0.09 & 0.12 & 0.72 & 1.09 & $10,561(2 \%)$ & $77(1 \%)$ \\
\hline & $-60,000$ to $-40,000$ & -0.00 & 0.09 & -0.01 & 1.00 & $18,992(3 \%)$ & $135(2 \%)$ \\
\hline & $-40,000$ to $-20,000$ & -0.08 & 0.08 & -1.08 & 0.92 & $29,613(5 \%)$ & 204(3\%) \\
\hline & $-20,000$ to 0 & -0.01 & 0.05 & -0.15 & 0.99 & $65,468(11 \%)$ & $709(12 \%)$ \\
\hline & 0 to 20,000 & 0 & Fixed & Fixed & 1 & $132,799(22 \%)$ & 1753(30\%) \\
\hline & 20,000 to 40,000 & 0.05 & 0.06 & 0.84 & 1.05 & $38,994(6 \%)$ & $356(6 \%)$ \\
\hline & 40,000 to 60,000 & -0.03 & 0.08 & -0.33 & 0.98 & $26,999(4 \%)$ & $213(4 \%)$ \\
\hline & 60,000 to 80,000 & 0.06 & 0.08 & 0.69 & 1.06 & $21,684(4 \%)$ & 184(3\%) \\
\hline & 80,000 to 100,000 & 0.12 & 0.08 & 1.37 & 1.12 & $19,393(3 \%)$ & $170(3 \%)$ \\
\hline & 100,000 to 150,000 & 0.08 & 0.06 & 1.31 & 1.09 & $43,924(7 \%)$ & $362(6 \%)$ \\
\hline & 150,000 to 200,000 & 0.05 & 0.07 & 0.72 & 1.05 & $36,455(6 \%)$ & $289(5 \%)$ \\
\hline & More than 200,000 & 0.25 & 0.05 & $5.45^{* * *}$ & 1.29 & $138,101(23 \%)$ & $1241(21 \%)$ \\
\hline \multirow[t]{2}{*}{ Education level } & Unknown & 0 & Fixed & Fixed & 1 & $243,871(40 \%)$ & $2622(45 \%)$ \\
\hline & Low & -0.04 & 0.05 & -0.96 & 0.96 & $135,166(22 \%)$ & 1138(19\%) \\
\hline
\end{tabular}


Table 1 Socio-demographic risk and protective factors for suicide in the Netherlands (Continued)

\begin{tabular}{|c|c|c|c|c|c|c|c|}
\hline Categories & Characteristics & $\begin{array}{l}\text { Beta } \\
\text { Parameters }\end{array}$ & Std. errors & t-tests & Odds-ratio & $\begin{array}{l}N(\%) \text { training } \\
\text { set }\end{array}$ & $\begin{array}{l}\mathrm{N}(\%) \text { suicides } \\
\text { training set }\end{array}$ \\
\hline & Middle & -0.05 & 0.04 & -1.31 & 0.95 & $126,604(21 \%)$ & $1338(23 \%)$ \\
\hline & High & -0.20 & 0.05 & $-4.28^{* * *}$ & 0.82 & $96,629(16 \%)$ & $756(13 \%)$ \\
\hline \multirow[t]{5}{*}{ Immigration background } & Dutch & 0 & Fixed & Fixed & 1 & $479,538(80 \%)$ & $4861(83 \%)$ \\
\hline & Western non-Dutch & 0.15 & 0.04 & $4.23^{* * *}$ & 1.17 & $55,507(9 \%)$ & $618(11 \%)$ \\
\hline & Non-Western & -0.47 & 0.05 & $-10.28^{* * *}$ & 0.63 & $67,225(11 \%)$ & $375(6 \%)$ \\
\hline & 1st generation immigrant & -0.33 & 0.04 & $-8.42^{* * *}$ & 0.72 & $66,276(11 \%)$ & $490(8 \%)$ \\
\hline & 2nd generation immigrant & 0.02 & 0.04 & 0.37 & 1.02 & $56,456(9 \%)$ & $503(9 \%)$ \\
\hline \multirow[t]{6}{*}{ Urbanicity } & Less than 10,000 people & 0.16 & 0.15 & 1.05 & 1.17 & $5125(1 \%)$ & $52(1 \%)$ \\
\hline & 10,000 to 100,000 people & 0.10 & 0.04 & $2.67^{* *}$ & 1.10 & $259,489(43 \%)$ & $2465(42 \%)$ \\
\hline & More than 100,000 people & 0 & Fixed & Fixed & 1 & $332,825(55 \%)$ & $3285(56 \%)$ \\
\hline & Low address density & -0.00 & 0.04 & -0.04 & 1.00 & $175,387(29 \%)$ & 1689(29\%) \\
\hline & Medium address density & -0.00 & 0.04 & -0.18 & 0.99 & $100,540(17 \%)$ & $974(17 \%)$ \\
\hline & High address density & 0 & Fixed & Fixed & 1 & $321,512(53 \%)$ & $3139(54 \%)$ \\
\hline \multirow[t]{10}{*}{ Place in household } & Kid living at home & 0 & Fixed & Fixed & 1 & $111,592(19 \%)$ & $464(8 \%)$ \\
\hline & Living alone & 0.56 & 0.08 & $7.15^{* * *}$ & 1.75 & $114,055(19 \%)$ & 2592(44\%) \\
\hline & $\begin{array}{l}\text { Part non married couple } \\
\text { without kids }\end{array}$ & -0.01 & 0.09 & -0.14 & 0.99 & $41,826(7 \%)$ & $378(6 \%)$ \\
\hline & Part non married couple with kids & -0.46 & 0.10 & $-4.47^{* * *}$ & 0.63 & $132,559(22 \%)$ & $990(17 \%)$ \\
\hline & Part married couple without kids & -0.45 & 0.08 & $-5.66^{* * *}$ & 0.64 & $32,483(5 \%)$ & 192(3\%) \\
\hline & Part married couple with kids & -0.55 & 0.08 & $-6.82^{* * *}$ & 0.58 & $128,513(21 \%)$ & $768(13 \%)$ \\
\hline & Member institutional household & 0.02 & 0.11 & 0.18 & 1.02 & $10,339(2 \%)$ & $183(3 \%)$ \\
\hline & Parent of single parent household & -0.10 & 0.11 & -0.95 & 0.91 & $22,115(4 \%)$ & $211(4 \%)$ \\
\hline & Reference person other household & 0.16 & 0.26 & 0.61 & 1.17 & $1578(0 \%)$ & $17(0 \%)$ \\
\hline & Other place household & -0.07 & 0.15 & -0.45 & 0.94 & $7210(1 \%)$ & $59(1 \%)$ \\
\hline Healthcare costs/year & Less than 1000 & 0 & Fixed & Fixed & 1 & $407,142(68 \%)$ & 2834(48\%) \\
\hline \multirow{3}{*}{$\begin{array}{l}\text { (excl. Mental } \\
\text { health care) }\end{array}$} & 1000 to 5000 & 0.33 & 0.03 & $9.85^{* * *}$ & 1.39 & $137,936(23 \%)$ & $1816(31 \%)$ \\
\hline & 5000 to 10,000 & 0.59 & 0.05 & $11.41^{* * *}$ & 1.80 & $29,758(5 \%)$ & $535(9 \%)$ \\
\hline & More than 10,000 & 0.80 & 0.05 & $16.56^{* * *}$ & 2.23 & $27,434(5 \%)$ & $669(11 \%)$ \\
\hline \multirow[t]{4}{*}{ Social benefits } & Unfit for work benefits (UFW) & 0.64 & 0.04 & $14.51^{* * *}$ & 1.89 & $25,196(4 \%)$ & $966(17 \%)$ \\
\hline & $\begin{array}{l}\text { Long term unemployment } \\
\text { benefits (LTU) }\end{array}$ & 0.23 & 0.06 & $3.94^{* * *}$ & 1.26 & $22,089(4 \%)$ & $577(10 \%)$ \\
\hline & $\begin{array}{l}\text { Short term unemployment } \\
\text { benefits }\end{array}$ & 0.19 & 0.06 & $3.33^{* * *}$ & 1.21 & $31,920(5 \%)$ & $406(7 \%)$ \\
\hline & Both UFW and LTU & -0.30 & 0.20 & -1.51 & 0.74 & 699(0\%) & $32(1 \%)$ \\
\hline \multirow[t]{10}{*}{ Province } & Groningen & 0 & Fixed & Fixed & 1 & $17,791(3 \%)$ & $232(4 \%)$ \\
\hline & Drenthe & -0.06 & 0.10 & -0.63 & 0.94 & $17,727(3 \%)$ & 194(3\%) \\
\hline & Utrecht & -0.21 & 0.08 & $-2.52^{*}$ & 0.81 & $44,708(7 \%)$ & $388(7 \%)$ \\
\hline & Noord-Holland & -0.23 & 0.07 & $-3.13^{* *}$ & 0.79 & $98,542(16 \%)$ & $902(15 \%)$ \\
\hline & Zuid-Holland & -0.21 & 0.07 & $-2.94^{* *}$ & 0.81 & $127,000(21 \%)$ & 1095(19\%) \\
\hline & Noord-Brabant & -0.01 & 0.07 & -0.17 & 0.99 & $89,342(15 \%)$ & $978(17 \%)$ \\
\hline & Limburg & -0.21 & 0.08 & $-2.61^{* *}$ & 0.81 & 40,603(7\%) & 409(7\%) \\
\hline & Overijssel & 0.23 & 0.08 & $2.72^{* *}$ & 1.26 & $40,315(7 \%)$ & $354(6 \%)$ \\
\hline & Flevoland & -0.11 & 0.12 & -0.92 & 0.90 & $13,721(2 \%)$ & $116(2 \%)$ \\
\hline & Zeeland & -0.11 & 0.11 & -0.98 & 0.90 & $13,449(2 \%)$ & $141(2 \%)$ \\
\hline
\end{tabular}


Table 1 Socio-demographic risk and protective factors for suicide in the Netherlands (Continued)

\begin{tabular}{llllllll}
\hline Categories & Characteristics & $\begin{array}{l}\text { Beta } \\
\text { Parameters }\end{array}$ & Std. errors & t-tests & Odds-ratio & $\begin{array}{l}\mathbf{N}(\%) \text { training } \\
\text { set }\end{array}$ & $\begin{array}{l}\mathbf{N}(\%) \text { suicides } \\
\text { training set }\end{array}$ \\
\hline \multirow{3}{*}{ Year } & Gelderland & -0.09 & 0.07 & -1.19 & 0.92 & $72,524(12 \%)$ & $725(12 \%)$ \\
& Friesland & 0.03 & 0.09 & 0.34 & 1.03 & $21,717(4 \%)$ & $268(5 \%)$ \\
& 2014 & 0 & Fixed & Fixed & 1 & $149,977(25 \%)$ & $1406(24 \%)$ \\
& 2015 & 0.10 & 0.04 & $2.59^{* *}$ & 1.10 & $150,595(25 \%)$ & $1468(25 \%)$ \\
& 2016 & 0.10 & 0.04 & $2.62^{* *}$ & 1.11 & $151,830(25 \%)$ & $1475(25 \%)$ \\
Other & 2017 & 0.14 & 0.04 & $3.70^{* * *}$ & 1.15 & $149,868(25 \%)$ & $1505(26 \%)$ \\
& Self Employed & -0.05 & 0.06 & -0.83 & 0.95 & $34,287(6 \%)$ & $335(6 \%)$ \\
& Main Earner of Household & -0.06 & 0.05 & -1.29 & 0.94 & $310,036(51 \%)$ & $4244(72 \%)$ \\
& Has a legal debt repayment plan & -0.30 & 0.19 & -1.58 & 0.74 & $1428(0 \%)$ & $31(1 \%)$ \\
& In mental health care & 2.04 & 0.03 & $64.97^{* * *}$ & 7.69 & $32,921(5 \%)$ & $2134(36 \%)$ \\
\hline
\end{tabular}

who die by suicide have mental health problems [10]. Additionally, physical healthcare being a risk factor could be explained due to hospitalisations for previous suicide attempts. However, due to the fact that the risk keeps increasing as physical health care costs increase, it is unlikely this would account for all of the increased risk.

This study did not observe significant differences between rural and urban municipalities. However, it is important to note that due to the high population

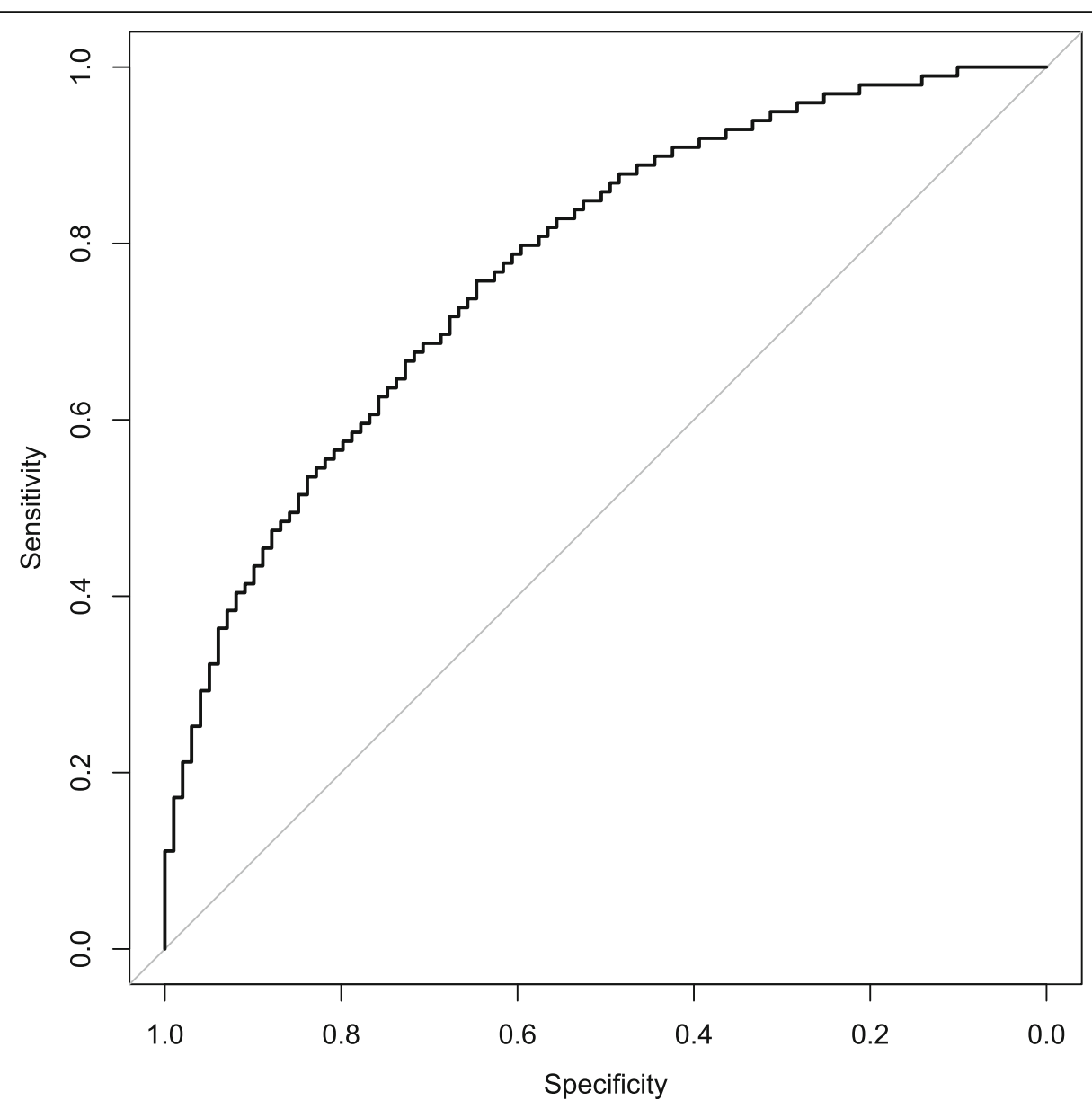

Fig. 1 Sensitivity-specificity plot of model predictions. The area under the curve is 0.77 
density in the Netherlands, most rural areas in the Netherlands might still be considered urban compared to rural areas in other countries.

Looking at raw frequencies, we see regional differences in the Netherlands [11]. These differences became much less when the effects of possible correlating risk factors were considered. This seems to indicate that the regional differences are primarily caused by the differences in the demographic makeup of the regions as opposed to specific local causes.

When we look at level of education, we see that being highly educated remains a protective factor. However, this only holds for the highest level of education and is not particularly protective. Especially when compared to the results of Phillips and Hempstead [12] who found large differences between the suicide rates among people with a high school degree and those among people with a college degree in the United States. Combined with the protective factor of income and the high correlation between level of education and income, this seems to suggest a proxy effect. The level of education might only be a protective factor due to the associated increase in income.

Our model has a reasonable fit with an AUC of 0.77, which is high for a model predicting suicide death [1] and comparable to the recent results of Zheng et al. [13] who used deep neural networks on electronic health records to predict suicide attempts (AUC of 0.769). It could be used to identify low, regular, or high-risk groups. However, the model is not usable to predict suicide risk in individuals. Suicide is a rare event that on average occurs in about 1 in 10,000 people a year. This means that even if you have a tenfold increase in predicted risk, you will still have 1000 false positives for each true positive.

Although then not useful for prediction on an individual level, the results from this study allow for targeted prevention measures at certain risk groups. For example, it would be possible to train social workers that are in regular contact with recipients of social benefits to be gatekeepers. Alternatively, high risk groups may be specifically targeted to raise awareness of suicide prevention hotlines within these groups. The authors also recommend that this study is repeated at regular intervals to see whether changes in public policy coincide with changes in risk groups.

The methodology used in this study allowed us to find robust risk and protective factors for suicide. However, with this methodology it is not possible to discover which specific combinations of risk factors or protective factors are especially dangerous or safe. Research has shown that the interactions of risk factors play a substantial role in suicide prediction and greatly improves model performance [13]. Therefore, having a proper understanding of such interactions will be of great importance in future research. We are currently working on a new machine learning model that will allow us to find significant interactions in a data-driven and hypothesis-free manner. Since we are doing this in a data driven and hypothesis-free manner, it both limits bias on which interactions to include and allows us to discover interactions that have not even been considered before.

\section{Acknowledgements \\ Not applicable.}

\section{Code availability}

Not applicable.

\section{Authors' contributions}

$G B, R M, S B$ and RG contributed to the concept and design of the study. RG contributed to the acquisition of the data from CBS. GB analyzed the data. GB drafted the paper. RM, SB, and RG helped revise and rewrite the paper. All authors have read and approved the final manuscript.

\section{Funding}

Research was funded by 113 zelfmoordpreventie (113 suicide prevention) which is itself mainly funded by the Ministry of Health, Welfare \& Sports of the Netherlands. All authors report no financial relationships with commercial interests.

Availability of data and materials

Due to privacy reasons the data used can only be accessed on the servers of Statistics Netherlands for which researchers can request access. Access is granted at the discretion of Statistics Netherlands.

\section{Declarations}

Ethics approval and consent to participate Not applicable.

\section{Consent for publication \\ Not applicable.}

\section{Competing interests}

None.

\section{Author details}

${ }^{1}$ Centrum Wiskunde \& Informatica, Science Park 123, 1098 XG Amsterdam, Netherlands. ${ }^{2}$ Vrije Universiteit Amsterdam, De Boelelaan 1111, $1081 \mathrm{HV}$ Amsterdam, Netherlands. ${ }^{3} 113$ zelfmoordpreventie, Paasheuvelweg 25, 1105 BP Amsterdam, Netherlands.

Received: 31 March 2021 Accepted: 8 August 2021

Published online: 18 September 2021

\section{References}

1. Franklin JC, Ribeiro JD, Fox KR, Bentley KH, Kleiman EM, Huang X, et al. Risk factors for suicidal thoughts and behaviors: a meta-analysis of 50 years of research. Psychol Bull. 2017;143(2):187-232. https://doi.org/10.1037/ bul0000084

2. Parra-Uribe I, Blasco-Fontecilla H, Garcia-Parés G, Martínez-Naval L, ValeroCoppin O, Cebrià-Meca A, et al. Risk of re-attempts and suicide death after a suicide attempt: a survival analysis. BMC psychiatry. 2017;17(1):163. https:// doi.org/10.1186/s12888-017-1317-z.

3. Choi SB, Lee W, Yoon JH, Won JU, Kim DW. Risk factors of suicide attempt among people with suicidal ideation in South Korea: a crosssectional study. BMC Public Health. 2017;17(1):579. https://doi.org/10.11 86/s12889-017-4491-5

4. Bhatt M, Perera S, Zielinski L, Eisen RB, Yeung S, el-Sheikh W, et al. Profile of suicide attempts and risk factors among psychiatric patients: a case-control 
study. PLoS One. 2018;13(2):e0192998. https://doi.org/10.1371/journal.pone. 0192998.

5. Ayhan G, Arnal R, Basurko C, About V, Pastre A, Pinganaud E, et al. Suicide risk among prisoners in French Guiana: prevalence and predictive factors. BMC Psychiatry. 2017;17(1):156. https://doi.org/10.1186/s12888-017-1320-4.

6. Gradus JL, Rosellini AJ, Horváth-Puhó E, Street AE, Galatzer-Levy I, Jiang T, et al. Prediction of sex-specific suicide risk using machine learning and single-payer health care registry data from Denmark. JAMA psychiatry. 2020 77(1):25-34. https://doi.org/10.1001/jamapsychiatry.2019.2905.

7. CBS Microdata. Available online: https://www.cbs.nl/nl-nl/onze-diensten/ maatwerk-en-microdata/microdata-zelf-onderzoek-doen (accessed on 24 July 2020).).

8. Bierlaire, M. (2020). A short introduction to PandasBiogeme. https://tra nsp-or.epfl.ch/documents/technicalReports/Bier20.pdf (accessed on 24 July 2020).

9. Boyd S, Vandenberghe $L$ (2004). Convex optimization. Cambridge university press. Chapters 4 and 7. doi:https://doi.org/10.1017/CBO9780511804441.

10. Arsenault-Lapierre G, Kim C, Turecki G. Psychiatric diagnoses in 3275 suicides: a meta-analysis. BMC psychiatry. 2004;4(1):37. https://doi.org/10.11 86/1471-244X-4-37.

11. Berkelmans G, van der Mei R, Bhulai S, Merelle S, Gilissen R. Demographic risk factors for suicide among youths in the Netherlands. Int J Environ Res Public Health. 2020;17(4):1182. https://doi.org/10.3390/ijerph17041182.

12. Phillips JA, Hempstead K. Differences in US suicide rates by educational attainment, 2000-2014. Am J Prev Med. 2017;53(4):e123-30. https://doi. org/10.1016/.amepre.2017.04.010

13. Zheng L, Wang O, Hao S, Ye C, Liu M, Xia M, et al. Development of an earlywarning system for high-risk patients for suicide attempt using deep learning and electronic health records. Transl Psychiatry. 2020;10(1):72. https://doi.org/10.1038/s41398-020-0684-2.

\section{Publisher's Note}

Springer Nature remains neutral with regard to jurisdictional claims in published maps and institutional affiliations.

Ready to submit your research? Choose BMC and benefit from:

- fast, convenient online submission

- thorough peer review by experienced researchers in your field

- rapid publication on acceptance

- support for research data, including large and complex data types

- gold Open Access which fosters wider collaboration and increased citations

- maximum visibility for your research: over $100 \mathrm{M}$ website views per year

At $\mathrm{BMC}$, research is always in progress.

Learn more biomedcentral.com/submissions 